Article

\title{
Passive Thermal Management of Tablet PCs Using Phase Change Materials: Intermittent Operation
}

\author{
Tousif Ahmed ${ }^{1}$, Maha Bhouri ${ }^{1}$, Dominic Groulx ${ }^{1,2, *}$ and Mary Anne White ${ }^{2,3}(\mathbb{C}$ \\ 1 Department of Mechanical Engineering, Dalhousie University, Halifax, NS B3H 4R2, Canada; \\ tousif@udel.edu (T.A.); Maha.Bhouri@Dal.Ca (M.B.) \\ 2 Clean Technology Research Institute, Dalhousie University, Halifax, NS B3H 4R2, Canada; \\ Mary.Anne.White@Dal.Ca \\ 3 Department of Chemistry, Dalhousie University, Halifax, NS B3H 4R2, Canada \\ * Correspondence: dominic.groulx@dal.ca
}

Received: 4 February 2019; Accepted: 25 February 2019; Published: 3 March 2019

check for updates

Featured Application: The results of this work see direct application in the passive thermal management of portable modern thin electronics, such as tablets and smartphones.

\begin{abstract}
This paper presents an experimental study of thermal management in a tablet PC under intermittent operation, with phase change materials (PCMs) encapsulated in a very thin aluminized laminate film container. It complements a study of the same system under continuous operation that was published in 2018. Two different types of PCMs were used for the experimental work; PT-37 and $n$-eicosane. A commercially available tablet PC was used as a test subject to ensure representative dimensions and material properties of every intricate part of the real tablet PC. For intermittent operation, the cycle used corresponds to fifteen minutes of operation (heat generation) followed by fifteen minutes of rest, to imitate a regular usage pattern of a tablet PC. It was observed that thin PCM thermal energy storage (TES) units are capable of providing a reduction in the rate of temperature increase during transient operations for both the electronics and the tablet cover. Reduction in peak temperature of the heat source and external surfaces of the tablet PC was also observed. At the maximum of $8 \mathrm{~W}$ operating power, $\mathrm{PCMs}$ were able to reduce the back-cover temperature by $20^{\circ} \mathrm{C}$. At all power inputs, heat storage in PCMs resulted in back-cover temperatures lower than $40^{\circ} \mathrm{C}$. Moreover, it was found that the PCM thermal management system tested was not affected by the inclination of the tablet PC. Results obtained from this study confirm that thin PCM encapsulation is indeed a suitable solution to control the temperature in tablet PCs during intermittent operation.
\end{abstract}

Keywords: phase change materials; thin thermal storage system; temperature management; modern portable electronics; intermittent operation

\section{Introduction}

Tablet computers (tablet PCs) have grown in use and capabilities in recent years and have several useful features that require high-density power sources to operate. However, the thermal management of these tablet PCs still relies on very basic passive cooling systems (internal heat spreaders, external natural convection). These passive cooling techniques can fall short in maintaining the required internal temperature of the tablet PC. Therefore, thermal management in a compact package has become a major concern for portable electronics manufacturers, mostly because active cooling is not an option in portable handheld devices. Localized high temperatures in handheld devices can lead to many potential threats towards the user or the device itself. Several studies [1-3] showed that handheld devices should maintain external operating temperatures below $42{ }^{\circ} \mathrm{C}-45^{\circ} \mathrm{C}$ for user 
comfort. In addition to user comfort, the longevity of electronic devices is also directly related to operating temperature. One study [4] revealed that $1{ }^{\circ} \mathrm{C}$ increase past operating temperature limit results in a $4 \%$ reduction of the reliability of electronic devices. More recently, users suffered serious injuries due to the explosion of smartphone batteries (which can happen to tablet PCs as well) caused by excessive device temperature.

A passive thermal management system is optimal for portable electronics cooling, as no extra power is required to operate the system with the additional advantage of silent operation. Phase change materials (PCMs) have gained significant attention for passive cooling of electronics due to their low cost, the wide range of physical properties they offer which facilitate flexibility in design, and their reliable service. PCMs have been studied for the temperature management of numerous types of larger scale electronics, more often than not combined for various heat sink designs. Those studies are not relevant to the work presented here since their sizes were at least one order of magnitude greater than what can be employed in thin portable electronics, and the power dissipation studied was also typically one to two orders of magnitude greater. The reader can find references to this research in the open literature.

Of greater importance to this work, a few studies have successfully implemented PCM-based thermal energy storage (TES) units for temperature stabilization in portable electronics having sizes approaching today's tablet PCs. Kandasamy et al. [5,6] showed both experimentally and numerically that paraffin wax is useful for the thermal management of electronic devices. In their earlier study [6], the authors considered both continuous and intermittent heat addition to the experimental system (a rectangular aluminum enclosure with $128 \mathrm{~mm} \times 10 \mathrm{~mm}$ internal cavity). Paraffin wax (PCM) provided a good transient response of the system for both continuous and intermittent usage. Since lower temperatures of the heater and external casing were encountered during intermittent operation, the authors indicated that for practical design, consideration of intermittent operation can reduce the TES unit weight and size greatly. In their later work [5], they used PCM-filled heatsinks (minimum height $10 \mathrm{~mm}$ ) on top of a dummy electronic system. They reported improvement of thermal performance over the baseline condition by using PCM filled heatsinks. No significant influence of the inclination of the device was reported in their studies. Tan and Tso [7] experimentally investigated a heat storage unit having cavities (depth not reported) filled with $n$-eicosane. They reported that the PCM can stabilize the temperature of the system and extend the operation time. In another investigation, Tan et al. [8] used three heatsinks ( $21 \mathrm{~mm}$ height, with and without fins) filled with $n$-eicosane and tested those under different usage loads. They found that it is reasonable to use PCM to reduce the rate of temperature increase in a mobile device during the transient heating phase. However, they concluded that using a PCM cooling system is effective only for intermittent-use mobile phones and not for continuous usage. In an experimental study, Alawadhi et al. [9] showed that a PCM-filled TES $\left(101 \times 68 \times 12 \mathrm{~mm}^{3}\right)$ is useful in controlling the temperature of electronic devices. In a more recent study, Gharbi et al. [10] investigated the cooling performance of paraffin as PCM in both continuous and intermittent operational regime. They showed that intermittent operation with increasing PCM melting-solidification cycle can substantially increase the critical time (defined as time to reach $77^{\circ} \mathrm{C}$ ). Breaking down a single $200 \mathrm{~min}$ of continuous heat addition cycle into eight consecutive cycles of melting-solidification resulted in a 320\% increase of the critical time. Weng et al. [11] evaluated a heat pipe charged with both tricosane and water. Their study showed that while mimicking an actual application with cyclic heat addition, the PCM can provide significantly lower heater temperature (almost $17^{\circ} \mathrm{C}$ reduction).

The common factor of the thicker PCM TES units used in all the studies mentioned above challenges the applicability of existing experimental work in practice, as typical tablet PCs are less than $10 \mathrm{~mm}$ thick, restricting space for PCMs within the device to only a few millimeters. Only a few papers in the literature deal with such thin systems. Tomizawa et al. [12] approached this issue by trapping PCM (PMCD-32SP paraffin) in polyethylene in a composite sheet form, referred to as MPCM/polyethylene composite. In one case, an MPCM/polyethylene sheet of $1.60 \mathrm{~mm}$ in thickness, which is ideal for 
installation in a tablet PC in a practical manner, was used. Although the MPCM/polyethylene sheet was successful in reducing the rate of temperature increase during transient heating, they showed that PCM alone is the best option for providing the highest delay before reaching the saturation temperature of approximately $50{ }^{\circ} \mathrm{C}$ for this study. The only other published experimental studies of thermal management of thin tablet PCs using PCM are from the authors' laboratory. Sponagle et al. [13], using a simplified experimental setup focusing on the thin $(<2 \mathrm{~mm})$ PCM TES units, found that they can delay the temperature increase of both the electronics and the cover by up to $34 \%$ compared to a case without PCM. Through this study, both continuous and intermittent operations were assessed. Additionally, Sponagle et al. [14] studied the effect of different PCM melting temperatures on the thermal behavior of tablet PCs. The authors concluded that PCMs with melting temperatures below $39^{\circ} \mathrm{C}$ are most suitable for thermal management of tablet PCs. In a previous study presenting the first approach to the current work, i.e., testing under continuous operation [15], PCM TES unit implementation issues in a real tablet PC were worked out and presented, and experimental results showed that under continuous operation ( $60 \mathrm{~min}$ of continuous heating at $2 \mathrm{~W}, 4 \mathrm{~W}, 6 \mathrm{~W}$ or $8 \mathrm{~W}$ ), the temperatures of both the system on a chip (SOC) and the cover were reduced compared to the case without PCM.

Consideration of an intermittent regime is of great importance since, during normal usage of tablet PCs, computational loads on the chip vary randomly from time to time based on the user utilization and the type of software, or apps, being used. It is expected that the typical tablet PC user will perform a high-power operation (e.g., online video call, HD recording and editing or power-intensive gaming) for a relatively short duration followed by a period of low usage or even idling of the device, releasing the chip from the heavy computational load and the associated heat generation. In recent literature, the performance of PCM based thermal storage units under intermittent applications has become an essential part of the overall research approach. Since typical usage power profiles of tablet PCs have not been published in the open literature, nor have they been shared by the various electronics companies, most studies rely on artificially generated temperature profiles for the study of thermal performance of PCM TES units. For a cyclic operation study, He et al. [16] applied 10 charging-discharging cycles consisting of $30 \mathrm{~min}$ of charging and $150 \mathrm{~min}$ of discharging on a $16 \mathrm{Ah} \mathrm{LiCoO}_{2}$ battery. They used a composite PCM (CPCM), containing paraffin, diffused into a copper foam as a thermal management system. Their thermal management system was reported to provide operating temperature below than the $50^{\circ} \mathrm{C}$ threshold temperature during cyclic operations. Wang et al. [17] utilized paraffin-EG composite encapsulated in an aluminum casing as battery thermal management (BTM) system. They employed three cycles of $60 \mathrm{~min}$ of battery discharging, $30 \mathrm{~min}$ of rest, and 150 min of charging to study the performance of PCM TES units under cyclic operation of the battery packs. Huang et al. [18] fabricated a form-stable flexible CPCM for the thermal management of Li-ion batteries that utilizes $n$-eicosane as PCM. They mimicked a transient working condition by applying $5 \mathrm{~min}$ of heating and $10 \mathrm{~min}$ of cooling. During the transient study, the CPCM system was able to reduce the operating temperature up to $10{ }^{\circ} \mathrm{C}$ while the Li-ion battery pack was rated to supply $10 \mathrm{~W}$ and $15 \mathrm{~W}$. Ali et al. [19] evaluated the thermal performance of a square pin-fin aluminum heat sink $(114 \mathrm{~mm} \times 114 \mathrm{~mm} \times 25 \mathrm{~mm})$ filled with $n$-eicosane installed on a mock-up electronic device operated at four different made up intermittent usage profiles. Their study investigated three cycles of heating and cooling where the duration of the heating phase varied from $5 \mathrm{~min}$ to $25 \mathrm{~min}$ and the duration of cooling phase varies from $10 \mathrm{~min}$ to $30 \mathrm{~min}$. Though these studies introduce the pathways to evaluate thermal performance of PCM TES units under intermittent operation, there are no standalone published studies looking at the in-depth intermittent operation of thin PCM TES units incorporated into realistic tablet PCs. The performance of recently developed slim PCM TES units by the current authors [15] has not been reported under any intermittent type usage situations yet.

Therefore, in this paper, results from a study using an available PCM-based thermal management system [15] operating intermittently are presented. The effects of power input levels, varying size of TES units, and inclination of the device, on the thermal response of the tablet PC were studied 
experimentally. These results are an essential complement to the previous continuous operation study and provide a solution to the issues imposed by the practical implementation of PCM-based TES units in tablet PCs.

\section{Experimental Setup}

\subsection{Phase Change Material}

As discussed in the previous study of continuous operation [15], the PCMs used were selected based on their melting temperature. From a numerical study by Sponagle et al. [20], PCMs with a melting temperature between $31^{\circ} \mathrm{C}$ and $43{ }^{\circ} \mathrm{C}$ showed the greatest promise here. Two PCMs were selected: $n$-eicosane (99\% pure, AS number-A13853, purchased from Alfa Aesar, Ward Hill, MA, USA) and PT-37 (a commercial PCM manufactured by PureTemp, Plymounth, MN, USA) with melting temperatures of $35.6{ }^{\circ} \mathrm{C}$ and $36.3^{\circ} \mathrm{C}$, respectively. Both PCMs have good chemical stability under melting-solidification cycles [21], a requirement for long-term use. It is also known that the corrosion of aluminized laminate film, the prospective encapsulation material used in the current research, was negligible with these PCMs [22]. Table 1 presents the thermophysical properties of $n$-eicosane and PT-37.

Table 1. Thermophysical properties of $n$-eicosane and PT-37 [21].

\begin{tabular}{lll}
\hline \multicolumn{1}{c}{ Properties } & \multicolumn{1}{c}{ n-Eicosane } & \multicolumn{1}{c}{ PT-37 } \\
\hline$\Delta_{f u s} H$ & $239 \pm 24 \mathrm{~J} / \mathrm{g}$ & $206 \pm 21 \mathrm{~J} / \mathrm{g}$ \\
$T_{m}$ & $35.6 \pm 1.5{ }^{\circ} \mathrm{C}$ & $36.4 \pm 1.5{ }^{\circ} \mathrm{C}$ \\
$C_{p, s}$ & $1.8 \pm 0.2 \mathrm{~J} / \mathrm{g} \mathrm{K}$ for $\mathrm{T}=20^{\circ} \mathrm{C}$ & $1.8 \pm 0.2 \mathrm{~J} / \mathrm{g} \mathrm{K}$ for $T=20^{\circ} \mathrm{C}$ \\
$C_{p, l}$ & $2.3 \pm 0.2 \mathrm{~J} / \mathrm{g} \mathrm{K}$ for $T=50^{\circ} \mathrm{C}$ & $2.1 \pm 0.2 \mathrm{~J} / \mathrm{g} \mathrm{K}$ for $T=50{ }^{\circ} \mathrm{C}$ \\
$k_{s}$ & $0.46 \pm 0.05 \mathrm{~W} / \mathrm{m} \mathrm{K}$ for $T=-21$ to $2{ }^{\circ} \mathrm{C}$ & $0.28 \pm 0.03 \mathrm{~W} / \mathrm{m} \mathrm{K}$ for $T=-21$ to $2{ }^{\circ} \mathrm{C}$ \\
$\rho$ & $0.79 \mathrm{~kg} / \mathrm{m}^{3}$ & $0.84 \mathrm{~kg} / \mathrm{m}^{3}$ \\
\hline
\end{tabular}

\subsection{Apparatus}

Figure 1a shows the test stand which held the experimental tablet PC using four 3D printed clamps allowing it to rotate at any angle. As the performance of the tablet PC might be affected by the natural convection occurring within the melted PCM and on the tablet PC's surface, it was necessary to include device inclination as a test parameter. A more complete description of the overall apparatus can be found in reference [15]. A thermal camera (ICI 7320 USB, accuracy level: $\pm 2{ }^{\circ} \mathrm{C}$ ) was also attached to the stand with a holder housed in a rack and pinion system used to obtain an appropriate focus on the test tablet PC. (The experimental tablet PC used for the study is shown in Figure 1b). It consisted of the original Windows tablet PC (Dell Venue 8 Pro) parts as a substrate (battery, screen, and casing) and had the following dimensions: $216 \mathrm{~mm} \times 116 \mathrm{~mm} \times 9 \mathrm{~mm}$. The original printed circuit board (PCB) including the CPU of the tablet PC was replaced by a mock PCB made from an FR4 copper clad board, which has similar thermal conductivity to the original PCB (through the plane and in-plane thermal conductivities of 0.343 and $1.059 \mathrm{~W} / \mathrm{m} \cdot \mathrm{K}$, respectively [23]). The heat dissipation from the tablet's electronics (mostly the CPU) was applied using a 1" square $\left(25.4 \times 25.4 \mathrm{~mm}^{2}\right)$ Kapton heater (Omega, Biel Biene, Switzerland, KHLV-101/10) with a rated power density of $10 \mathrm{~W} / \mathrm{in}^{2}$ at $28 \mathrm{VAC}$. This specific heater is the best one available to replicate the dimensional and power attributes of an actual CPU in the tablet PC. 


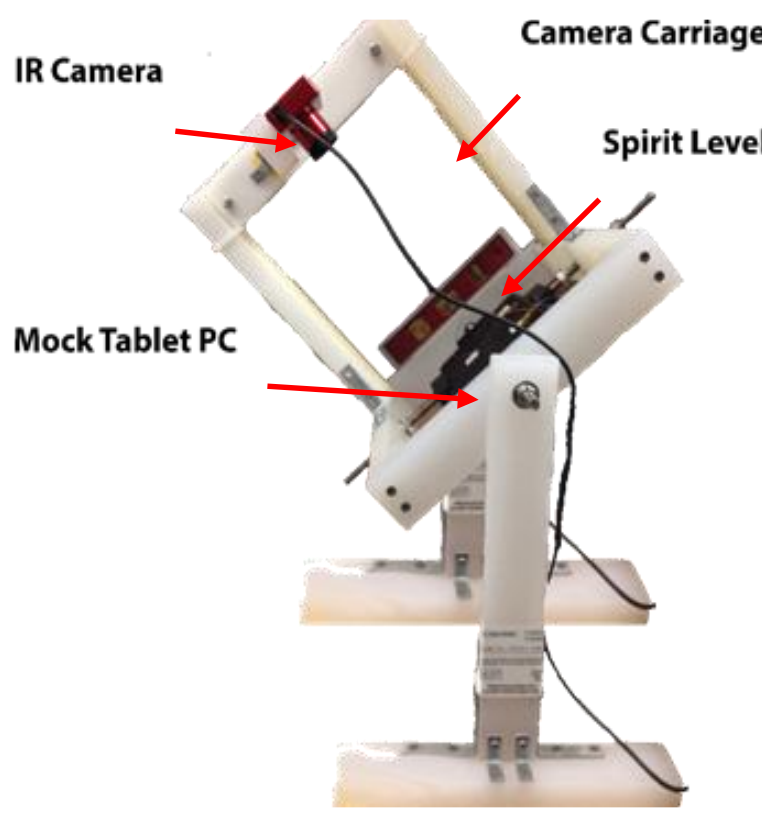

(a)

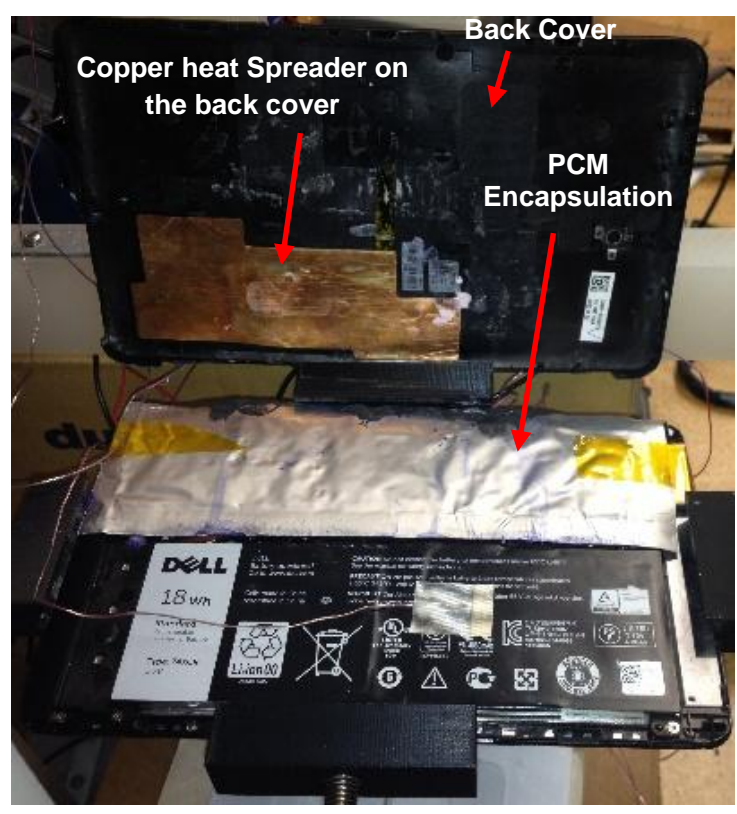

(b)

Figure 1. Photograph of the experimental setup showing (a) the inclined test stand and (b) the mock tablet PC with Size 2 PCM (phase change material) encapsulation on display. IR: Infrared.

Nine Type-T thermocouples (Omega SA1-T-SC) were used in the mock tablet PC to measure temperatures on the front surface, back cover, and internal components. The locations of these thermocouples in the mock tablet PC are shown in Figure 2a. The front thermocouples are denoted using the letter $\mathrm{F}$, and the letter $\mathrm{B}$ for the thermocouples on the back surface. Three encapsulations with different areas and masses were used: Size 1: $152.4 \times 66 \mathrm{~mm}^{2}, 16 \mathrm{~g}$; Size 2: $177.8 \times 38 \mathrm{~mm}^{2}, 11 \mathrm{~g}$; and Size 3: $177.8 \times 86 \mathrm{~mm}^{2}, 25 \mathrm{~g}$; the average thickness was $2 \mathrm{~mm}$ for all encapsulations. Different sizes of encapsulation with similar thickness were chosen to determine the effect of size and PCM amount on the thermal behavior of the system. Moreover, while the smallest (Size 2 in Figure 2b) encapsulation is mostly useful to control the temperature of the electronics, Size 1 and Size 3 can help reduce temperature of the battery as well (since parts of these two encapsulations sit on the top of the battery) [15]. However, in the current study the battery has not been considered as a heat source.
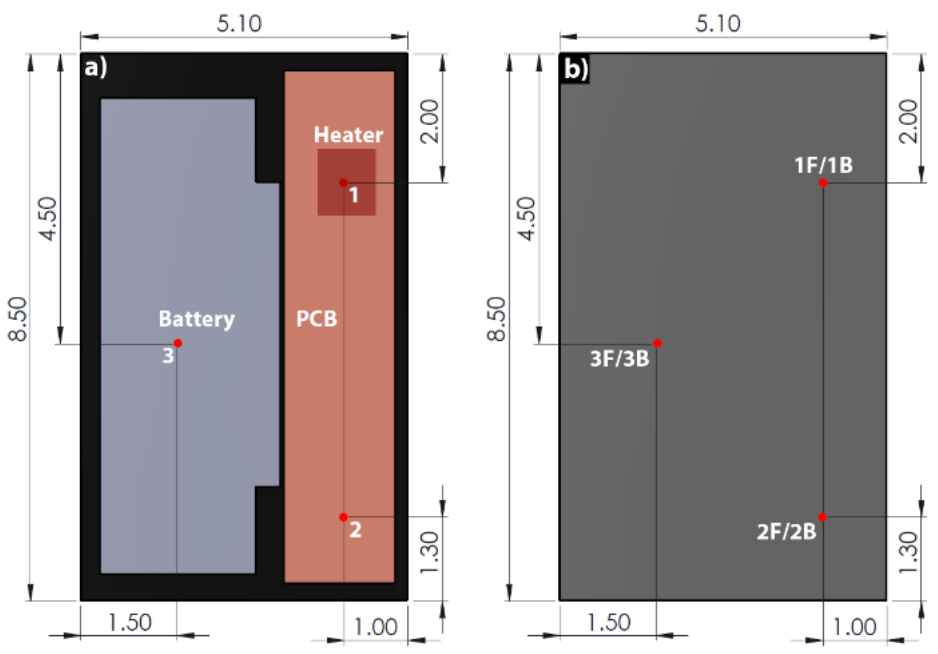

(a)

Figure 2. Cont. 

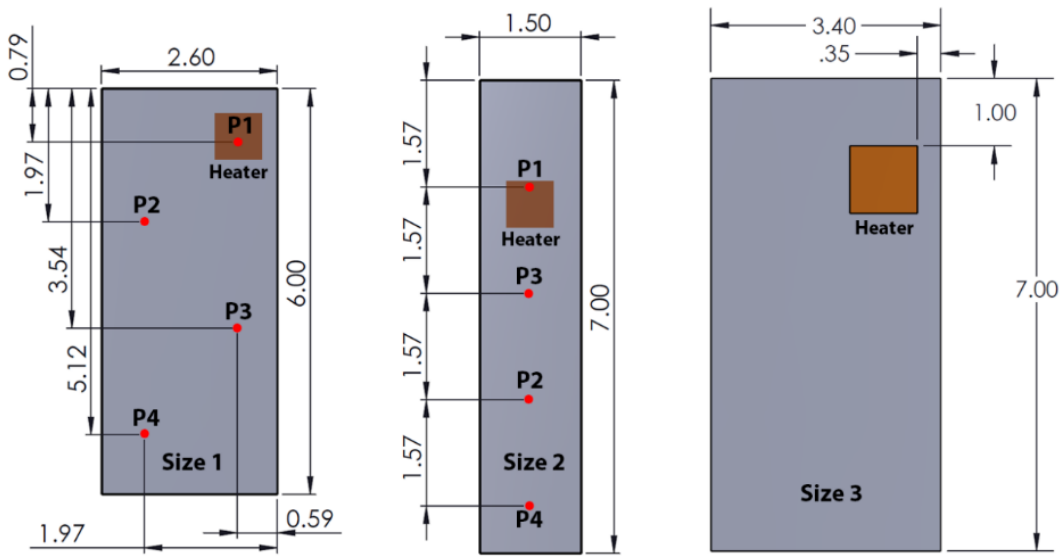

(b)
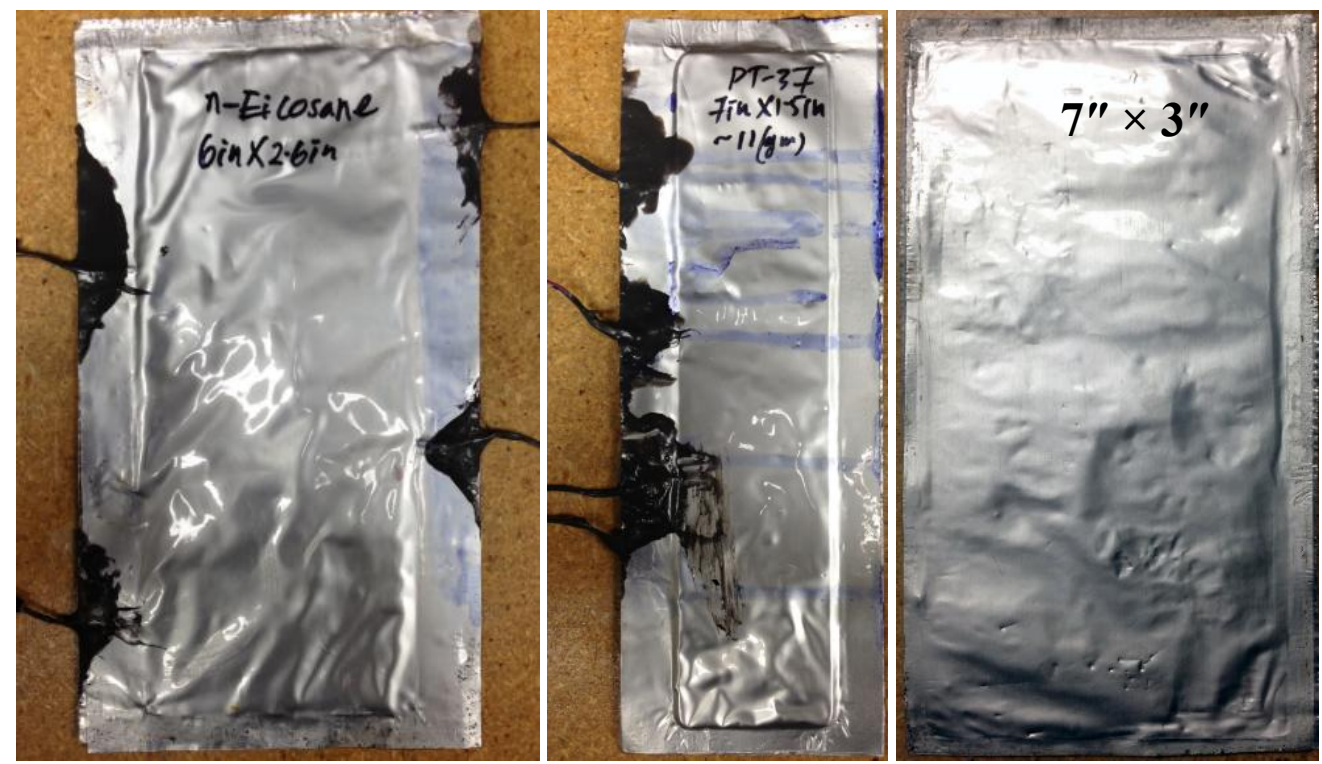

(c)

Figure 2. (a) Positions of thermocouples attached to internal components and to front and back surfaces of the mock tablet PC (F-Front, B-Back), (b) schematics of the three different sized encapsulations with positions of thermocouples relative to the tablet PC heater (dimensions in inches) (c) photographs of PCM encapsulations: Size 1 (Left), Size 2 (middle), Size 3 (right).

Aluminized laminate film was used as the encapsulation material, and due to its flexible nature, the thickness of the encapsulations varied from a minimum of $1.7 \mathrm{~mm}$ to a maximum of $2.2 \mathrm{~mm}$; additional information on the laminate film used can be found in references $[22,24]$. Figure $2 b$ shows the schematics of the three encapsulations, with the locations of four Type $T$ thermocouples inserted in Size 1 and Size 2 encapsulations to observe the thermal behavior of the PCMs during the experiments. Photographs of the three encapsulations are presented in Figure 2c.

It was observed that the PCM partially melted in the three sizes of PCM TES unit used. This clearly made it difficult to determine the actual amount of latent heat participating in the storage process during the experiment. Therefore, to clearly observe the effect of different levels of latent heat participation, three additional smaller encapsulations were created for each PCM. They were positioned directly on top of the heat source where complete PCM melting would be expected. These encapsulations had the same base area $\left(2^{\prime \prime} \times 22^{\prime \prime}, 51 \times 51 \mathrm{~mm}^{2}\right)$ but different thicknesses: thickness 1 was $0.13^{\prime \prime}(3 \mathrm{~mm}, 6 \mathrm{~g} \mathrm{PCM})$, thickness 2 was $0.16^{\prime \prime}(4 \mathrm{~mm}, 8 \mathrm{~g}$ PCM), and thickness 3 was $0.20 "$ ( $5 \mathrm{~mm}, 10 \mathrm{~g}$ PCM). A summary of the dimensions of all encapsulations used in this study, as well as the associated latent heat thermal storage capacity for each, can be found in Table 2. 
Table 2. Summary of dimensional attributes of encapsulations, amount of PCMs, and latent heat used.

\begin{tabular}{lllccc}
\hline \multirow{2}{*}{ Encapsulation } & \multicolumn{1}{c}{ Base Area } & $\begin{array}{c}\text { Average } \\
\text { Thickness }\end{array}$ & $\begin{array}{c}\text { Amount of } \\
\text { PCM, } m_{\text {pcm }}\end{array}$ & \multicolumn{2}{c}{ Total Latent Heat $(\mathbf{k J}) m_{\text {pcm }} \times \boldsymbol{\Delta}_{\text {fus }} H$} \\
\cline { 5 - 6 } & & & & n-eicosane & PT-37 \\
\hline Size 1 & $6^{\prime \prime} \times 2.6^{\prime \prime}\left(152.4 \times 66 \mathrm{~mm}^{2}\right)$ & $1 / 16^{\prime \prime}(2 \mathrm{~mm})$ & $16 \mathrm{~g}$ & 3.82 & 3.25 \\
Size 2 & $7^{\prime \prime} \times 1.5^{\prime \prime}\left(177.8 \times 38 \mathrm{~mm}^{2}\right)$ & $1 / 16^{\prime \prime}(2 \mathrm{~mm})$ & $11 \mathrm{~g}$ & 2.63 & 2.27 \\
Size 3 & $7^{\prime \prime} \times 3.4^{\prime \prime}\left(177.8 \times 86 \mathrm{~mm}^{2}\right)$ & $1 / 16^{\prime \prime}(2 \mathrm{~mm})$ & $25 \mathrm{~g}$ & 6.00 & 5.15 \\
Thickness 1 & $2^{\prime \prime} \times 2^{\prime \prime}\left(51 \times 51 \mathrm{~mm}^{2}\right)$ & $0.13^{\prime \prime}(3 \mathrm{~mm})$ & $6 \mathrm{~g}$ & 1.42 & 1.23 \\
Thickness 2 & $2^{\prime \prime} \times 2^{\prime \prime}\left(51 \times 51 \mathrm{~mm}^{2}\right)$ & $0.16^{\prime \prime}(4 \mathrm{~mm})$ & $8 \mathrm{~g}$ & 1.89 & 1.64 \\
Thickness 3 & $2^{\prime \prime} \times 2^{\prime \prime}\left(51 \times 51 \mathrm{~mm}^{2}\right)$ & $0.20^{\prime \prime}(5 \mathrm{~mm})$ & $10 \mathrm{~g}$ & 2.36 & 2.05 \\
\hline
\end{tabular}

\subsection{Procedure}

The operations of the experimental tablet $\mathrm{PC}$ in a horizontal position (inclination $0^{\circ}$ ) and without any PCM-based TES unit were considered baseline conditions for the intermittent operation study. During the experiments, the heater was controlled by a National Instrument's (NI) relay module (model NI 9481) which was connected in series between the variac and the heater. The variac was set to supply a certain AC voltage in order to generate the required heat input. LabVIEW was used to turn the relay module on and off, thus turning on and off the heater as per the requirement of the tablet PC's intermittent operation. All experiments for the experimental tablet PC with and without PCM-based TES units were conducted for three cycles of $15 \mathrm{~min}$ of heat input followed by $15 \mathrm{~min}$ with the heater off.

The LabVIEW program also recorded all thermocouples data at $1 \mathrm{~Hz}$ frequency. During each experiment with a given PCM TES unit, the ambient temperature was between $20^{\circ} \mathrm{C}$ and $22^{\circ} \mathrm{C}$. It is clear that ambient temperature will play an important and direct role on the overall thermal behavior of such systems, starting from the initial temperature of the device even before usage, and future work would be required to study this aspect of the problem. Table 3 summarizes all experiments carried out during the intermittent operation stage of the research.

Table 3. Summary of experiments done in the intermittent operation.

\begin{tabular}{|c|c|c|c|c|c|}
\hline Observations & PCMs & $\begin{array}{l}\text { Size of TES Unit } \\
\text { (Mass of PCMs) }\end{array}$ & Inclination & Power Input & Operation Mode \\
\hline $\begin{array}{l}\text { Melting-Solidification } \\
\text { of PCMs }\end{array}$ & $\begin{array}{l}n \text {-eicosane } \\
\text { PT-37 }\end{array}$ & $\begin{array}{l}\text { Size } 1(16 \mathrm{~g}) \\
\text { Size } 2(11 \mathrm{~g})\end{array}$ & $\begin{array}{l}0^{\circ} \text { (horizontal) } \\
45^{\circ} \\
90^{\circ} \text { (vertical) }\end{array}$ & $\begin{array}{l}2 \mathrm{~W} \\
4 \mathrm{~W} \\
6 \mathrm{~W} \\
6 \mathrm{~W} \\
8 \mathrm{~W}\end{array}$ & $\begin{array}{l}3 \text { cycles of: } \\
\text { Charging-15 min. } \\
\text { Discharging-15 min. }\end{array}$ \\
\hline $\begin{array}{c}\text { Performance of the } \\
\text { Tablet PC }\end{array}$ & $\begin{array}{c}\text { n-eicosane } \\
\text { PT-37 }\end{array}$ & $\begin{array}{l}\text { Size } 1(16 \mathrm{~g}) \\
\text { Size } 2(11 \mathrm{~g}) \\
\text { Size } 3(25 \mathrm{~g}) \\
2^{\prime \prime} \times 2^{\prime \prime} \times 0.12^{\prime \prime}(6 \mathrm{~g}) \\
2^{\prime \prime} \times 2^{\prime \prime} \times 0.16^{\prime \prime}(8 \mathrm{~g}) \\
2^{\prime \prime} \times 2^{\prime \prime} \times 0.20^{\prime \prime}(10 \mathrm{~g})\end{array}$ & $\begin{array}{l}0^{\circ} \text { (horizontal) } \\
45^{\circ} \\
90^{\circ} \text { (vertical) }\end{array}$ & $\begin{array}{l}2 \mathrm{~W} \\
2 \mathrm{~W} \\
4 \mathrm{~W} \\
6 \mathrm{~W} \\
8 \mathrm{~W}\end{array}$ & $\begin{array}{l}3 \text { cycles of: } \\
\text { Charging-15 min. } \\
\text { Discharging-15 min. }\end{array}$ \\
\hline
\end{tabular}

\subsection{Sources of Uncertainties}

The uncertainties of the type-T thermocouples are $\pm 0.5{ }^{\circ} \mathrm{C}$. The uncertainties of the power measurement were up to $\pm 8 \%$ due mostly to the voltage supply uncertainty of up to $\pm 4 \%$. The uncertainty in supplied voltage was measure by taking multiple reading from a multi-meter for a given set position of the dial in the variac. Then the uncertainty in power was calculated from the power-voltage relationship (Equation (1)) provided by the heater manufacturer:

$$
q^{\prime \prime}=\frac{P_{R} V^{2}}{V_{R}^{2}}
$$

where rated power density $\left(P_{R}\right)$ and voltage $\left(V_{R}\right)$ for current heater are $10 \mathrm{~W} / \mathrm{in}^{2}$ and $28 \mathrm{VAC}$, respectively. Maximum uncertainties in the supplied power and supplied voltage for different power 
input levels can be seen in Table 4 . The inconsistency in voltage supply mainly occurred due to the voltage drop of the variac caused by other lab equipment using the same power line; those uncertainties are still low and did not influence repeatability of the experiments, as demonstrated in the first half of this study [15].

Table 4. Uncertainties in supplied voltage and supplied power.

\begin{tabular}{ccc}
\hline Power Input & $\begin{array}{c}\text { Maximum Uncertainty } \\
\text { in the Supplied Voltage }\end{array}$ & $\begin{array}{c}\text { Maximum Uncertainty } \\
\text { in the Supplied Power }\end{array}$ \\
\hline $2 \mathrm{~W}$ & $\pm 4 \%$ & $\pm 8 \%$ \\
$4 \mathrm{~W}$ & $\pm 2.8 \%$ & $\pm 5.75 \%$ \\
$6 \mathrm{~W}$ & $\pm 2.3 \%$ & $\pm 5 \%$ \\
$8 \mathrm{~W}$ & $\pm 2 \%$ & $\pm 3.75 \%$ \\
\hline
\end{tabular}

\section{Results and Discussion}

\subsection{Thermal Response of the PCMs}

A typical melting curve for a Size $2 n$-eicosane TES unit at $45^{\circ}$ inclination and $8 \mathrm{~W}$ power input can be seen in Figure 3. Temperatures at points $\mathrm{P} 2$ and $\mathrm{P} 4$ indicate that at $8 \mathrm{~W}$ of power input, the melting of $n$-eicosane inside the TES unit was not complete. During the discharging phase, the time required to reject the latent heat (almost $5 \mathrm{~min}$ ) is significantly lower compared to the continuous operation mode which required almost $15 \mathrm{~min}$ [15]. This difference can be attributed to the higher latent heat storage during the continuous operation even at the same heat input level $(8 \mathrm{~W})$ due to longer operation time. After 15 min of discharging, the temperatures registered at points $\mathrm{P} 1$ and $\mathrm{P} 3$ were almost $30{ }^{\circ} \mathrm{C}$, still higher than room temperature $\left(20^{\circ} \mathrm{C}\right)$. Therefore, after $15 \mathrm{~min}$ of discharging, the PCM still stores some sensible heat which in turns results in a gradual increase of the peak temperature after $15 \mathrm{~min}$ of charging in subsequent cycles, as can be seen from Figure 3.

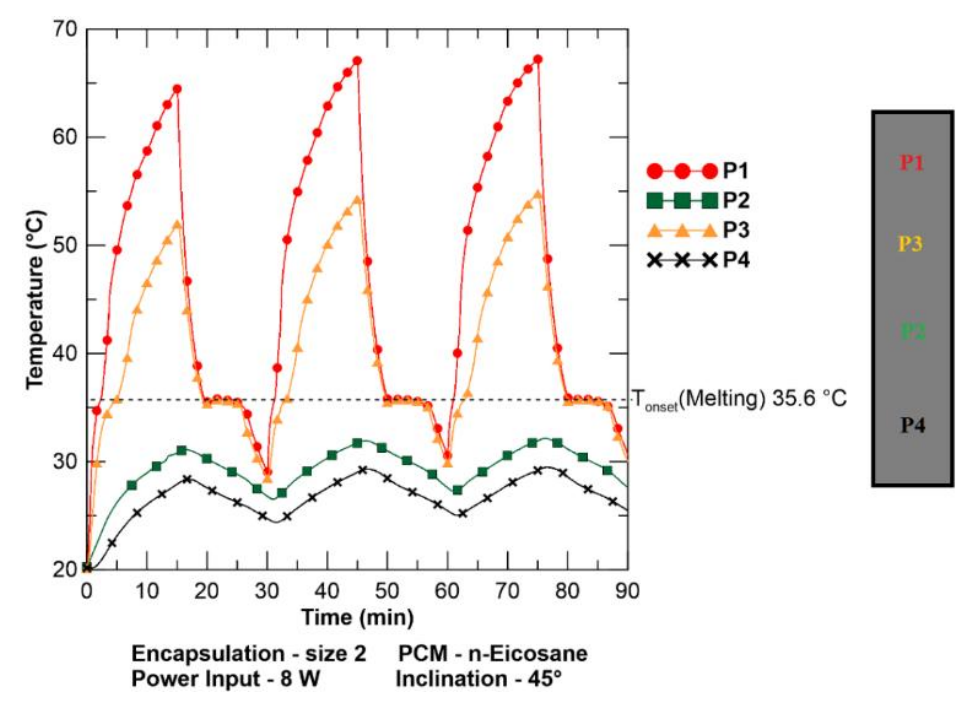

Figure 3. Melting curves of $n$-eicosane for Size 2 TES unit at $45^{\circ}$ inclination and $8 \mathrm{~W}$ power input.

\subsubsection{Influence of Inclination}

Figure 4 shows the thermal responses of four thermocouples inserted into Size 1 PCM-based TES units with both PCMs for different inclination angles when the power level was kept at $6 \mathrm{~W}$. Identical curves during sensible heat storage imply that conduction is the main mode of heat transfer. The effect of inclination is not very noticeable after $15 \mathrm{~min}$ of charging, as can be seen from Figure $4 \mathrm{a}, \mathrm{b}$. The fluctuations among $0^{\circ}, 45^{\circ}$, and $90^{\circ}$ inclination were attributed to the natural convection on the tablet 
PC surfaces in the case of the continuous operation [18]. Unlike the continuous operation, no PCM melting was observed at point P3 after 15 min of intermittent charging. The previous continuous operation study showed that typically a time interval of $20 \mathrm{~min}$ of charging (heat addition) is required to melt the PCM at point P3 during continuous operation.

The temperatures at points P2, P3, and P4 are below the melting point of both PCMs. As a result, the PCM at these points did not contribute to any latent heat storage.
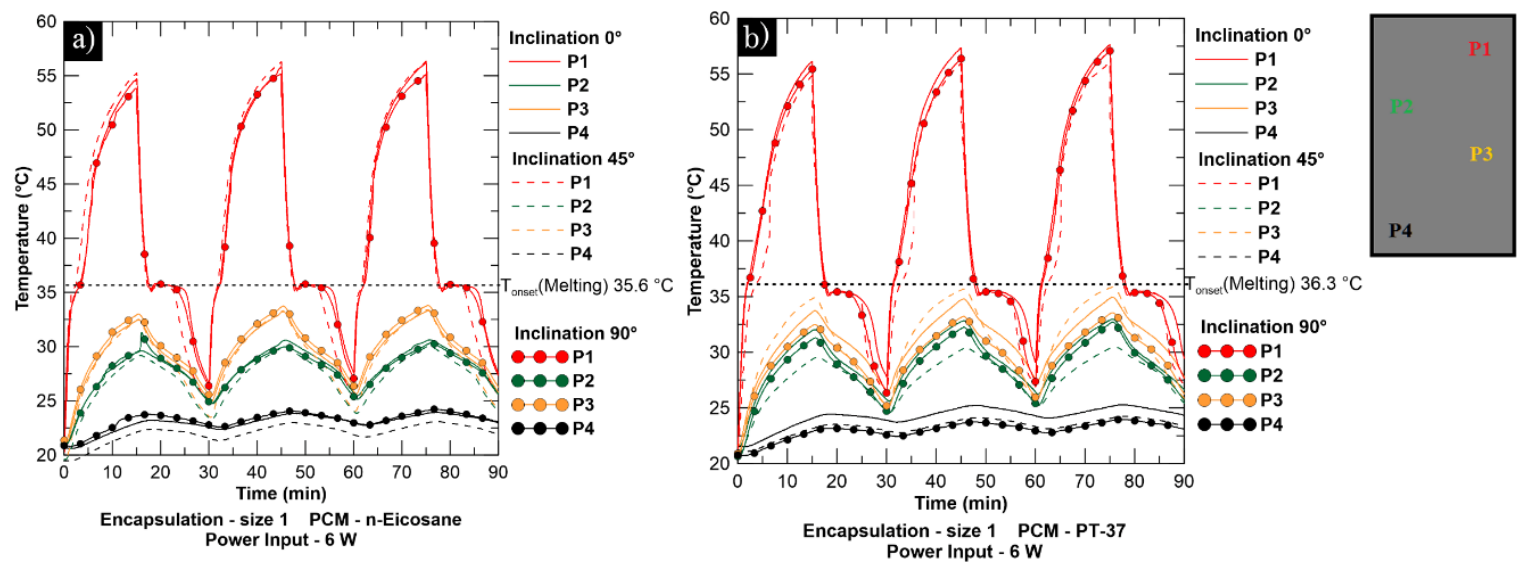

Figure 4. Influence of inclination on PCM melting for intermittent operation at $6 \mathrm{~W}$ power input with Size 1 PCM TES Unit: (a) n-eicosane and (b) PT-37.

\subsubsection{Influence of Power Input Levels}

Figure 5 shows the influence of different power input levels on the melting of the two PCMs for Size 1 PCM-based TES unit at $0^{\circ}$ inclination. It is apparent that the peak temperature of PCM at point $\mathrm{P} 1$ is proportional to the heat input from the heater. Moreover, an increasing trend of temperature in the following cycles is also observed which mainly occurs due to only partial heat rejection during the discharging phase. For instance, at $8 \mathrm{~W}$ power input, the sensible heat release was almost negligible in the second and the third cycle of discharging phase for PT-37 (Figure 5b). Higher heat input results in more latent heat storage which results in a longer duration of latent heat release during the discharging phase. At lower heat input, the melting rate was also lower which results in a less steep slope for the melting curves. Due to shorter duration of the charging (heating) phase, the PCM at point P3 does not reach the melting temperature and no PCM melting was observed.
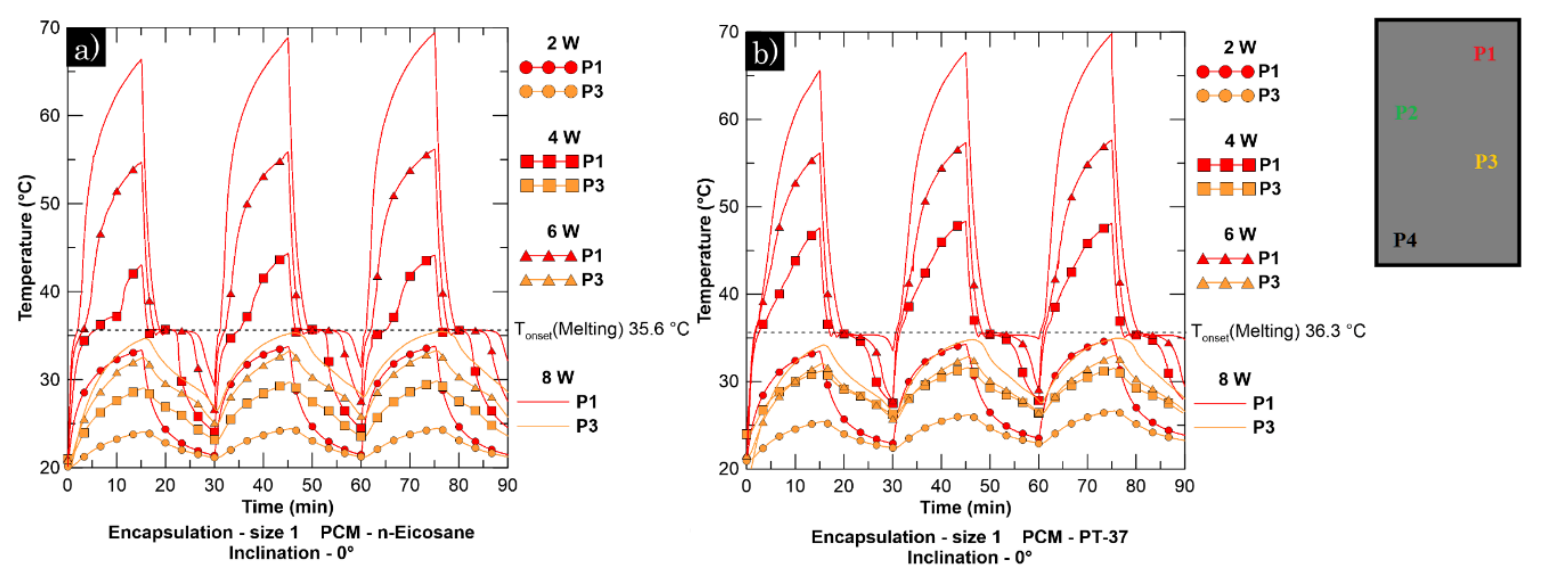

Figure 5. Influence of power input levels on PCM melting for intermittent operation at $0^{\circ}$ inclination with Size 1 PCM TES Unit: (a) n-eicosane and (b) PT-37. 


\subsubsection{Influence of TES Unit Size}

Figure 6 shows the influence of the PCM-based TES unit size on the melting curve of both PCMs, $n$-eicosane and PT-37, at $6 \mathrm{~W}$ power input and $0^{\circ}$ inclination. After $15 \mathrm{~min}$ of charging, Size $1 n$-eicosane TES unit resulted in almost $5{ }^{\circ} \mathrm{C}$ higher peak temperature at point $\mathrm{P} 1$ compared to the Size $2 n$-eicosane TES unit (Figure 6a). Similar occurrences were observed in the case of the continuous operation after 15 min of charging. In the case of PT-37, the deviation in the peak temperature of point P1 was almost $10{ }^{\circ} \mathrm{C}$ in the first cycle (Figure 6b). This further deviation occured due to a higher amount of PT-37 melting in the Size 2 TES unit compared to the Size $2 n$-eicosane TES unit. Loading of more PCM on the top of the heater in the case of Size 2 PT-37 TES unit might be one of the reasons behind this phenomenon. Note the slower temperature increase rate in the charging curve (Figure 6b, Size 2).
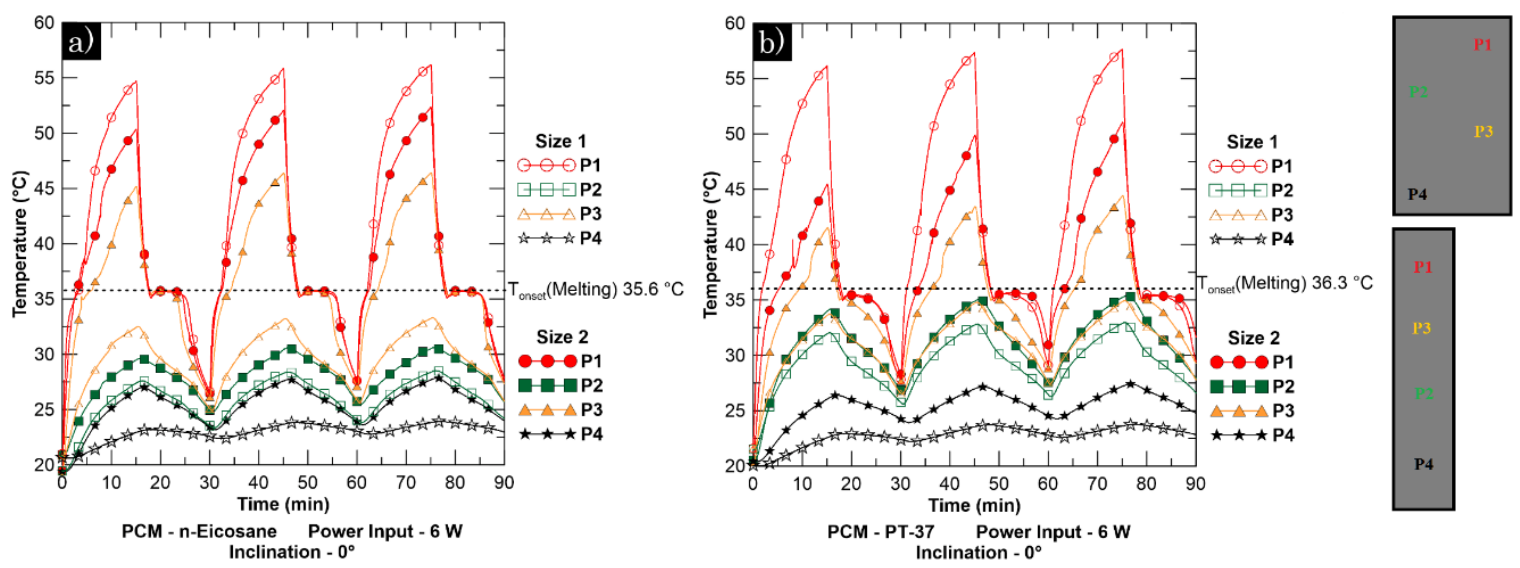

Figure 6. Influence of PCM TES size on PCM melting at $6 \mathrm{~W}$ power input and $0^{\circ}$ inclination: (a) n-eicosane and (b) PT-37.

Due to the close proximity of the P3 thermocouple to the heater, significant melting of the PCM was observed with Size 2 PCM TES unit for both PCMs. With the Size 1 PCM TES unit, the PCM at point $\mathrm{P} 3$ only stored sensible heat without experiencing any melting. In the continuous operation with Size 1 PCM TES unit, melting of PCM at the P3 point was observed after a sufficient amount of time. But after $15 \mathrm{~min}$, the point P3 temperature did not reach the melting point of the PCM. Hence, results for intermittent operation conform to the results found with continuous operation studies.

\subsection{Performance of the Tablet PC}

The temperature response of the experimental tablet $\mathrm{PC}$ at different power input levels can be seen in Figure 7. Point 2F had a higher temperature than point 2B, even though the heater was placed on the back side of the PCB. This difference mostly resulted from a large metal stiffener residing between the PCB and the display which conducts and spreads heat on the front side better than the backside at that location. Moreover, thermal resistance on the back was higher compared to the front side due to the presence of air gaps between the circuit board and the back cover. Based on all baseline operations, only temperature variations of the heater (point 1), P1B on the back cover and point 1F on the front display are considered as performance parameters.

A typical comparison of Size 1 PT-37 TES unit performance on the tablet PC with baseline operation at $6 \mathrm{~W}$ heat input and $0^{\circ}$ inclination can be seen in Figure 8 . The back surface just above the heater (point 1B) experienced an almost $22^{\circ} \mathrm{C}$ reduction in the temperature compared to the baseline operation case. The point on the front (display), in line with the heater (point $1 \mathrm{~F}$ ), has almost $5{ }^{\circ} \mathrm{C}$ reduction using the PCM-based TES unit. Moreover, throughout the whole intermittent operation, the back-cover temperature never exceeded the user comfort limit of $40{ }^{\circ} \mathrm{C}$ at $6 \mathrm{~W}$ power input. Additionally, the peak temperature after each charging cycle is found to be stable and unchanged. 
As a result, only three cycles were deemed to be sufficient to study the effectiveness of PCM TES units under intermittent operation.
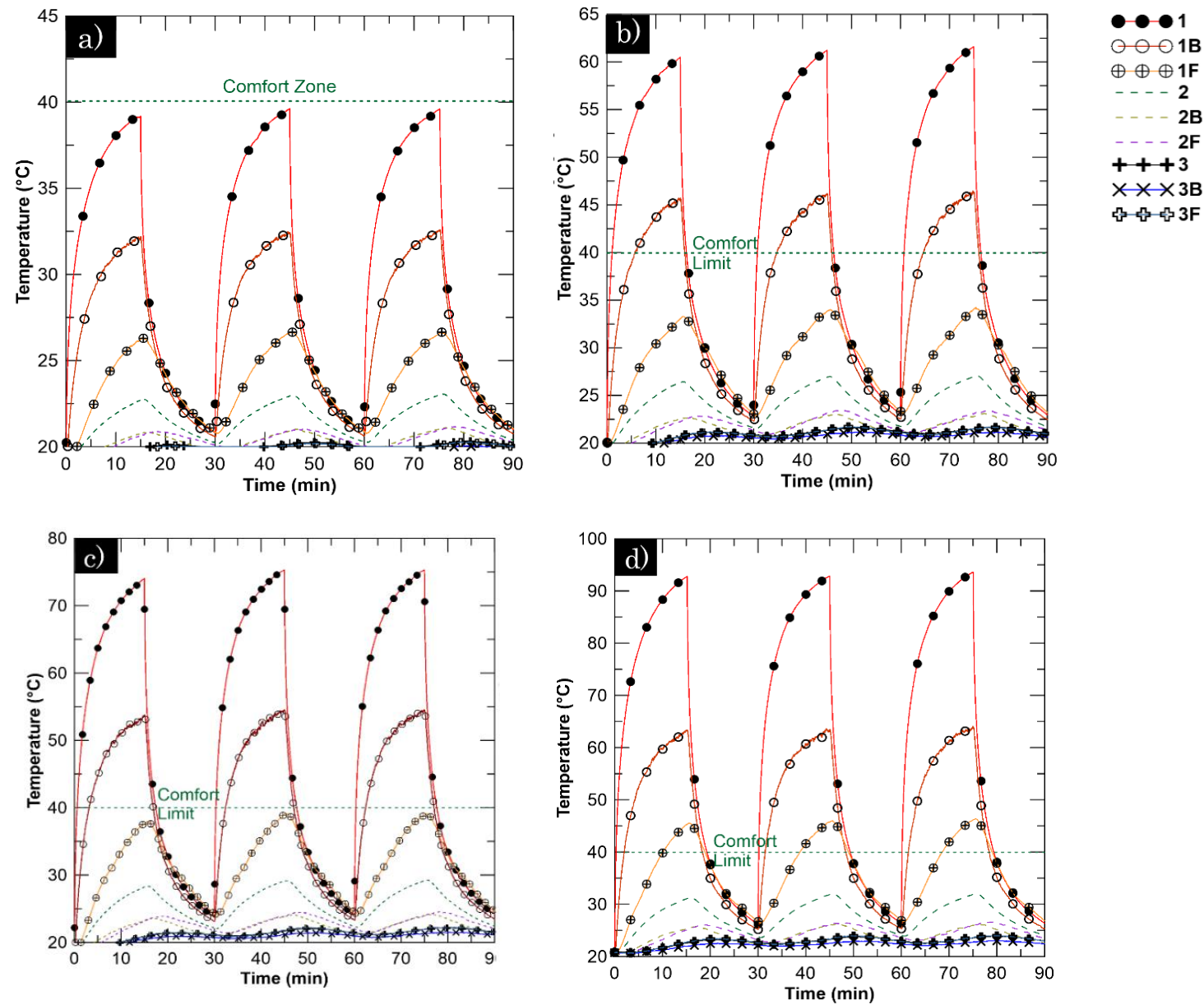

Figure 7. The baseline temperature profile for the experimental tablet $\mathrm{PC}$ at various power input without any PCM TES units: (a) $2 \mathrm{~W}$, (b) $4 \mathrm{~W}$, (c) $6 \mathrm{~W}$ and (d) $8 \mathrm{~W}$.

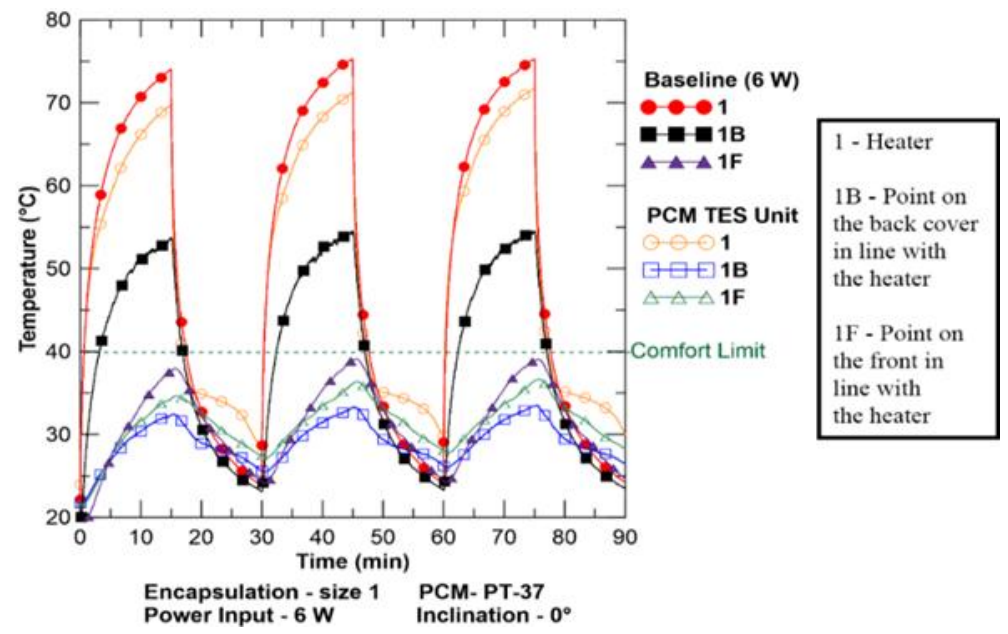

Figure 8. Influence of Size $1 n$-eicosane TES unit on the thermal response of the experimental tablet PC at $0^{\circ}$ inclination and $6 \mathrm{~W}$ power input. 


\subsubsection{Influence of Inclination}

Figure 9 shows the thermal response of the experimental tablet $\mathrm{PC}$ for various angular orientations at $6 \mathrm{~W}$ power input with Size 1 PCM TES unit. No significant variations in the peak temperature of the heater are found with inclination. Deviations in the temperatures of points $1 \mathrm{~B}$ and $1 \mathrm{~F}$ are not significant after $15 \mathrm{~min}$ of charging during the intermittent operation. This deviation would be the same as the continuous operation if sufficient time during the charging phase is allowed under intermittent operation. Typically, the deviation at point $1 \mathrm{~B}$ and $1 \mathrm{~F}$ after $15 \mathrm{~min}$ of charging is smaller than the deviation after 60 min of continuous charging.
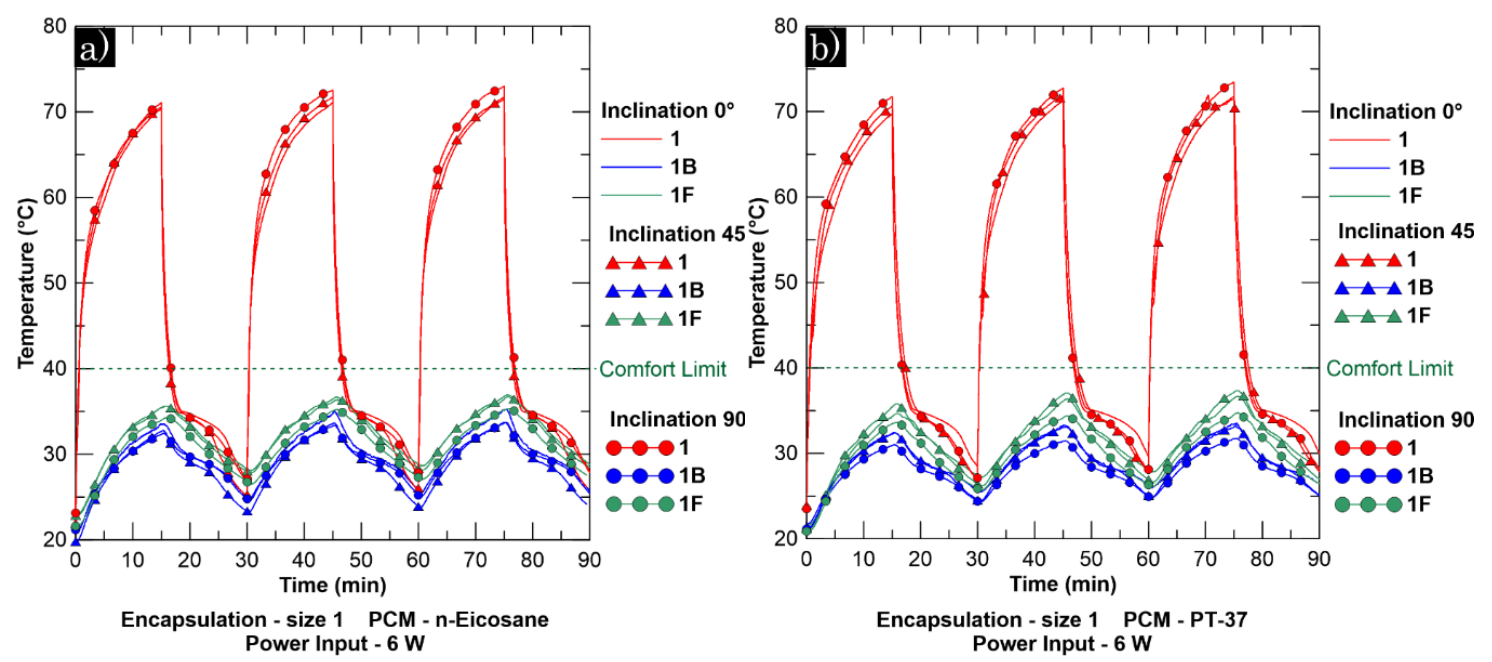

Figure 9. Influence of inclination on the thermal response of the experimental tablet PC at $6 \mathrm{~W}$ power input with Size 1 PCM TES Unit: (a) n-eicosane and (b) PT-37.

Considering the slight influence of orientation on the thermal performance of the tablet PC and the favorable back-cover temperatures, the PCM-based TES units can be expected to work reliably in practical situations with intermittent usage.

\subsubsection{Influence of Power Input Levels}

The effect of power input levels on the thermal performance of the experimental tablet PC with Size 1 PCM TES units with both PCMs and at $0^{\circ}$ inclination can be seen from Figure 10. The peak heater temperature was found to be proportional to the power input levels. At $8 \mathrm{~W}$ power input, the heater (point 1) temperature reached almost $90{ }^{\circ} \mathrm{C}$ for $n$-eicosane and PT-37 based TES units (slightly more than $90{ }^{\circ} \mathrm{C}$ in PT-37 due to power input uncertainty). This means that even at intermittent operation the heater temperature crossed the threshold of $85^{\circ} \mathrm{C}$, the maximum chip temperature allowed in electronic devices for safe operations [25]. Hence, it is suggested that $8 \mathrm{~W}$ power input should be avoided in this particular tablet PC to stay within the allowable maximum chip temperature using thin PCM-based TES units similar to the continuous operation. However, back-cover temperatures for all power input levels were within the user comfort limit. 

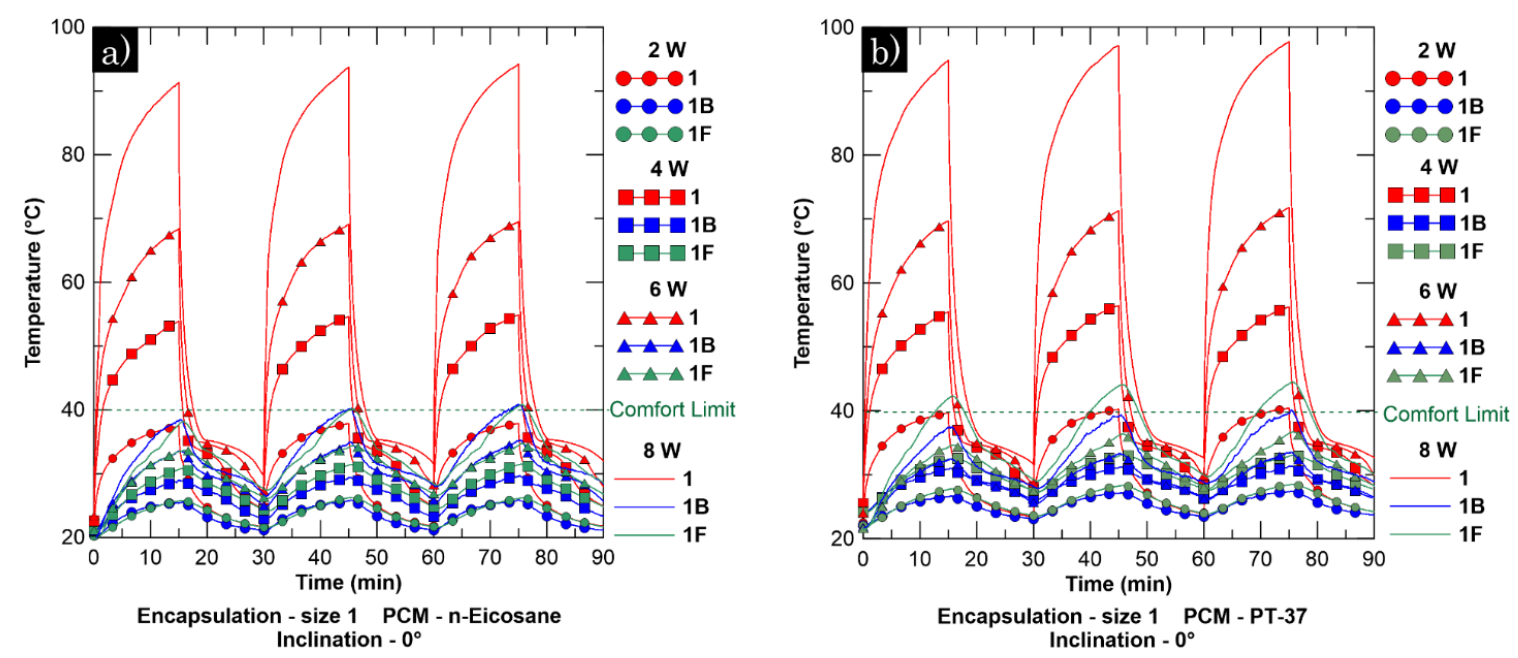

Figure 10. Influence of power input levels on the thermal response of the experimental tablet PC at $0^{\circ}$ inclination with Size 1 PCM TES unit: (a) n-eicosane and (b) PT-37.

\subsubsection{Influence of TES Unit Size}

The influence of the PCM TES unit size on the thermal response of the experimental tablet PC at $6 \mathrm{~W}$ power input and $0^{\circ}$ inclination can be seen from Figure 11. The variation of the thermal response between $n$-eicosane and PT-37 TES units due to the differences in their latent heat was not significant. Both $n$-eicosane and PT-37 Size 3 TES units provided similar temperatures on the back cover (point 1B) after 15 min of charging. Having higher heat storage and allowing for the smallest air gap inside the tablet PC, the Size 3 TES unit resulted in better thermal performance of the tablet PC compared to the two other TES units. Size 2 PCM TES unit resulted in the highest back-cover temperature due to a smaller size and least heat stored in PCMs. A slight increase in the peak temperature of the heater, display, and back cover in subsequent cycles could be noticed. These peak temperatures largely depended on the amount of latent heat rejected at the discharging phase. This fact was more pronounced in systems with PCMs with higher latent heat, as can be seen in the following section.
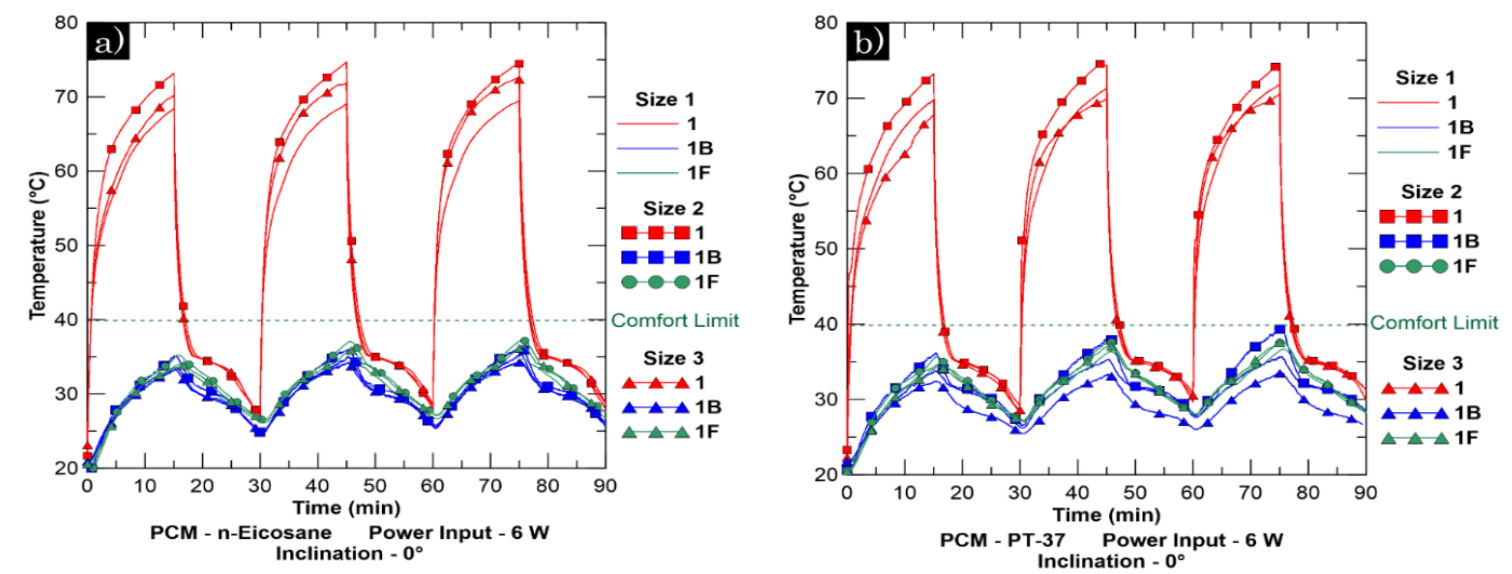

Figure 11. Influence of PCM TES size on the thermal response of the experimental tablet PC at $6 \mathrm{~W}$ power input and $0^{\circ}$ inclination: (a) $n$-eicosane and (b) PT-37.

\subsubsection{Influence of Varying Latent Heat}

Figure 12 shows the comparison between a typical Size 1 PCM TES unit and smaller encapsulations with different latent heats for PT-37 PCM. The heater temperature for the smaller encapsulations was reduced significantly and the back-cover temperature is significantly higher. Due to higher internal thermal resistance from the presence of air gaps in the tablet PC, heat tends to escape through the 
PCM TES units to the back cover thus leading to a high-temperature hot spot on the back cover. It is interesting to note that Size 1 PCM TES unit had relatively quicker heat rejection compared to smaller TES units. As a result, in subsequent cycles, peak temperatures of the heater and back cover remained almost constant. On the other hand, due to partial latent heat rejection during the discharging phase, peak temperatures of the heater and back cover increased in subsequent cycles with smaller TES units (a similar occurrence was observed in reference [10]) since heat rejection to the environment is governed simply by Newton's law of cooling, i.e., the temperature difference between the surface and the room air, the heated surface area and the convection coefficient which is essentially constant in this case.

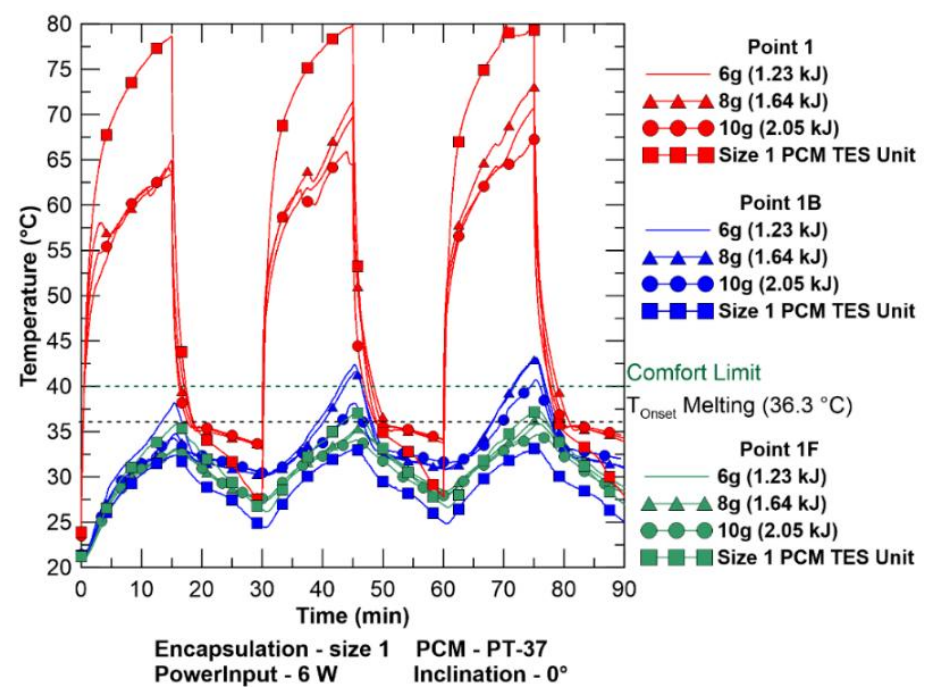

Figure 12. Comparison between Size 1 PT-37 TES unit with smaller PT-37 TES units having different latent heats at $6 \mathrm{~W}$ power input and $45^{\circ}$ inclination: performance of the tablet PC.

Figure 13 shows a very little deviation of peak heater temperature with varying latent heat after $15 \mathrm{~min}$. For continuous operation, the influence of varying latent heat on the heater temperature was more distinct in the 20 to $40 \mathrm{~min}$ heating range [15]. Since heating was stopped after 15 min during the intermittent operation, the influence of varying latent heat was negligible.
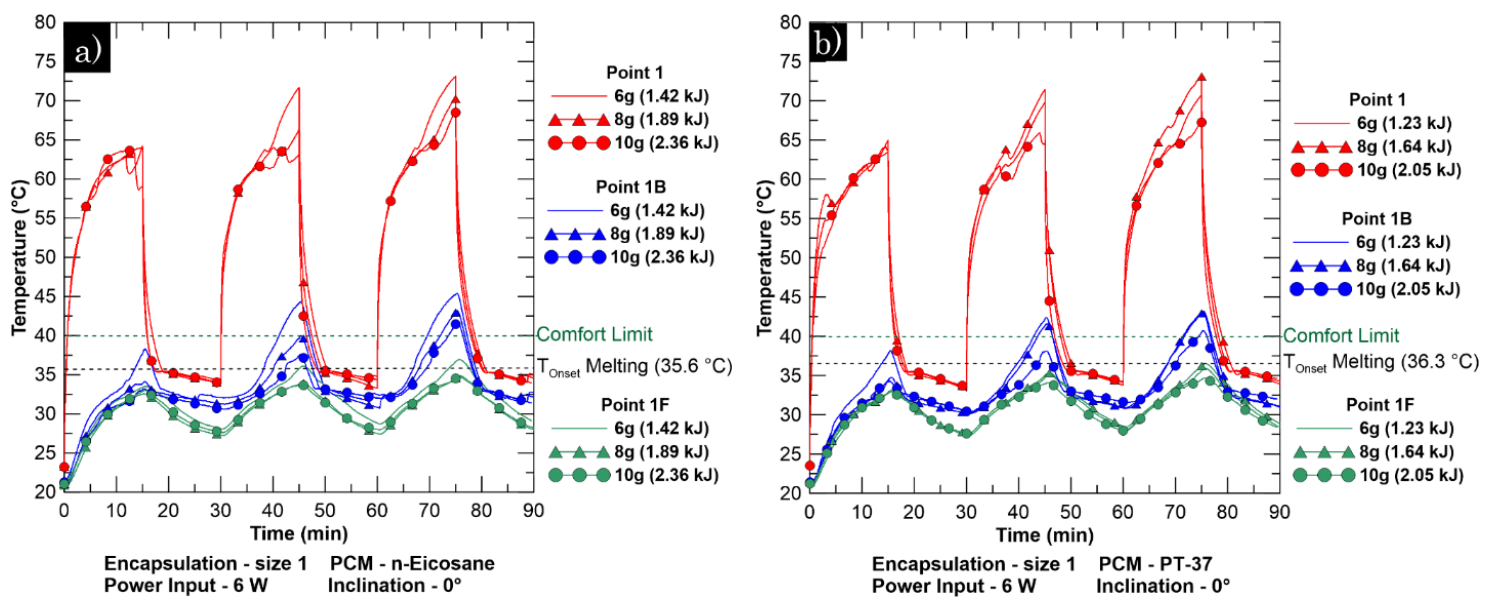

Figure 13. Influence of varying latent heat on the thermal response of the experimental tablet PC at $6 \mathrm{~W}$ power input and $45^{\circ}$ inclination: (a) $n$-eicosane, and (b) PT-37.

Due to less heat storage in the TES unit with $6 \mathrm{~g}$ of PCM, the back-cover temperature was slightly higher compared to the two other $(8 \mathrm{~g}, 10 \mathrm{~g})$ PCM-based TES units. The back-cover temperature was 
increased from $37^{\circ} \mathrm{C}$ to $45^{\circ} \mathrm{C}$ in the final cycle of operation for both PCMs due to stored heat built up at the end of each previous cycles ( $6 \mathrm{~g}$ case). Hence, smaller PCM-based TES units placed on the heat source should be used along with heat spreaders to distribute heat uniformly and avoid a concentrated hotspot on the back cover.

Comparing Figure 13a,b, it is evident that though $n$-eicosane has $14.5 \%$ higher latent heat than PT-37, in operation, this difference does not play a significant role. After each heating cycle, the heater, front, and back cover of the tablet PC experienced similar peak temperatures. Similar trends were observed in results presented in earlier sections.

\section{Conclusions}

This study experimentally justified the effectiveness of using PCM TES units in a tablet PC. The PCM TES units were tested under different orientations of the device, different heat input levels, different latent heats, and different TES unit sizes. To represent real applications, the intermittent regime was studied for three cycles of operation. Two PCMs, n-eicosane and PT-37, were selected, based on melting temperatures that best suit the operating comfort limit required by the tablet PC users. Smaller PCM-based TES units, placed only on the heat generating components (i.e., heater) were introduced and investigated to access the viability of component-level selective thermal management concept. The following conclusions resulted from the current work:

1. Applications of PCM TES units lead to significant temperature reduction after each 15-min charging cycle. Back-cover temperature reduction is more than $20^{\circ} \mathrm{C}$ at $6 \mathrm{~W}$ power input. At $8 \mathrm{~W}$ heat input level, the tablet PC temperature was maintained below the comfort limit of $40^{\circ} \mathrm{C}$ at all times with PCM TES units, although the SOC temperature exceeded the allowed maximum.

2. The effect of tablet PC orientation on thermal performance of TES units is negligible.

3. PCM TES units provide a comfortable back-cover temperature at all tested power input levels ( $2 \mathrm{~W}$ to $8 \mathrm{~W}$ ). At higher power input level, more PCM melts, storing more latent heat. As a result, a longer time is required to release latent heat in the discharging phase at higher power input levels. Though PCM TES units provide acceptable back-cover temperature of the tablet PC at $8 \mathrm{~W}$ power input, the chip temperature rises beyond $85^{\circ} \mathrm{C}$. Hence, for the system studied here, power input of $8 \mathrm{~W}$ and higher should be avoided for reliable operation of the tablet PC combined with current PCM TES units.

4. Larger PCM TES units result in better thermal performance due to the removal of most of the air gap and higher thermal storage from more PCM.

5. Smaller PCM-based TES units placed on heat-generating components (i.e., heater) provide the best temperature reduction of the heater, even compared to regular PCM TES units, since the temperature reduction is significantly increased due to larger amounts of PCM melting during the charging phase. However, the back-cover temperature suffers from slightly higher temperatures (hot spot) with these types of PCM TES units.

6. The thermal behavior of the tablet PC does not show significant sensitivity to the variety of PCMs tested, although both PCMs have slightly different thermophysical properties.

PCMs encapsulated in the aluminized laminate film have been proven to be a practical solution for portable electronic device thermal management. This study did not look at the impact of ambient temperature on the initial temperature of the device, the impact of ambient temperature on the cooling of the device, or the possible influence of a change in ambient temperature on the optimal selection of PCM. Those questions will be investigated in future work.

Author Contributions: Conceptualization, D.G., M.A.W.; methodology, T.A., D.G.; formal analysis, T.A.; investigation, T.A.; writing-original draft preparation, T.A.; writing-review and editing, M.B., D.G., M.A.W.; supervision, M.B., D.G.; project administration, D.G.; funding acquisition, D.G., M.A.W.

Funding: This research was funded by Intel Corporation, grant number 9388323. 
Acknowledgments: The authors thank Intel Corporation for the financial and technical support which made this work possible, along with the Natural Sciences and Engineering Research Council of Canada (NSERC), the Nova Scotia Government (Graduate Scholarship program) and the Canada Foundation for Innovation (CFI) for further laboratory financial assistance.

Conflicts of Interest: The authors declare no conflict of interest.

\section{References}

1. Patapoutian, A.; Peier, A.M.; Story, G.M.; Viswanath, V. ThermoTRP channels and beyond: Mechanisms of temperature sensation. Nat. Rev. Neurosci. 2003, 4, 529-539. [CrossRef] [PubMed]

2. Greenspan, J.D.; Roy, E.A.; Caldwell, P.A.; Farooq, N.S. Thermosensory intensity and affect throughout the perceptible range. Somatosens. Mot. Res. 2003, 20, 19-26. [CrossRef] [PubMed]

3. Story, G.M. The emerging role of TRP channels in mechanisms of temperature and pain sensation. Curr. Neuropharmacol. 2006, 4, 183. [CrossRef] [PubMed]

4. McPherson, J.W. Reliability Physics and Engineering: Time-To-Failure Modeling; Springer: Berlin, Germany, 2010.

5. Kandasamy, R.; Wang, X.-Q.; Mujumdar, A.S. Transient cooling of electronics using phase change material (PCM)-based heat sinks. Appl. Therm. Eng. 2008, 28, 1047-1057. [CrossRef]

6. Kandasamy, R.; Wang, X.-Q.; Mujumdar, A.S. Application of phase change materials in thermal management of electronics. Appl. Therm. Eng. 2007, 27, 2822-2832. [CrossRef]

7. Tan, F.; Tso, C.P. Cooling of mobile electronic devices using phase change materials. Appl. Therm. Eng. 2004, 24, 159-169. [CrossRef]

8. Tan, F.; Shen, W.; Fok, S. Thermal Performance of PCM-Cooled Mobile Phone. In Proceedings of the IEEE 2009 11th Electronics Packaging Technology Conference, Singapore, 9-11 December 2009; pp. 640-645.

9. Alawadhi, E.M.; Amon, C.H. PCM thermal control unit for portable electronic devices: Experimental and numerical studies. IEEE Trans. Compon. Packag. Technol. 2003, 26, 116-125. [CrossRef]

10. Gharbi, S.; Harmand, S.; Jabrallah, S.B. Experimental study of the cooling performance of phase change material with discrete heat sources-Continuous and intermittent regimes. Appl. Therm. Eng. 2017, 111, 103-111. [CrossRef]

11. Weng, Y.-C.; Cho, H.-P.; Chang, C.-C.; Chen, S.-L. Heat pipe with PCM for electronic cooling. Appl. Energy 2011, 88, 1825-1833. [CrossRef]

12. Tomizawa, Y.; Sasaki, K.; Kuroda, A.; Takeda, R.; Kaito, Y. Experimental and numerical study on phase change material (PCM) for thermal management of mobile devices. Appl. Therm. Eng. 2016, 98, 320-329. [CrossRef]

13. Sponagle, B.; Maranda, S.; Groulx, D. Investigation of the Thermal Behaviour of Thin Phase Change Material Packages as a Solution to Temperature Control in Electronics. In Proceedings of the ASME 2017 Summer Heat Transfer Conference, Bellevue, WA, USA, 9-14 July 2017.

14. Sponagle, B.N.; Groulx, D. Numerical Study of Temperature Control in Tablet Computers using Phase Change Material Thermal Energy Storage. In Proceedings of the 4th International Forum on Heat Transfer, IFHT2016, Sendai, Japan, 2-4 November 2016.

15. Ahmed, T.; Bhouri, M.; Groulx, D.; White, M.A. Passive thermal management of tablet PCs using phase change materials: Continuous operation. Int. J. Therm. Sci. 2018, 134, 101-115. [CrossRef]

16. He, J.; Yang, X.; Zhang, G. A phase change material with enhanced thermal conductivity and secondary heat dissipation capability by introducing a binary thermal conductive skeleton for battery thermal management. Appl. Therm. Eng. 2019, 148, 984-991. [CrossRef]

17. Wang, W.; Zhang, X.; Xin, C.; Rao, Z. An experimental study on thermal management of lithium ion battery packs using an improved passive method. Appl. Therm. Eng. 2018, 134, 163-170. [CrossRef]

18. Huang, Y.-H.; Cheng, W.-L.; Zhao, R. Thermal management of Li-ion battery pack with the application of flexible form-stable composite phase change materials. Energy Convers. Manag. 2019, 182, 9-20. [CrossRef]

19. Ali, H.M.; Arshad, A.; Janjua, M.M.; Baig, W.; Sajjad, U. Thermal performance of LHSU for electronics under steady and transient operations modes. Int. J. Heat Mass Transf. 2018, 127, 1223-1232. [CrossRef]

20. Sponagle, B.; Groulx, D. Thermal Modeling of Tablets: Temperature Management using Phase Change Materials. In Proceedings of the 1st Thermal and Fluid Engineering Summer Conference, TFESC, New York, NY, USA, 9-12 August 2015. 
21. Ahmed, T.; Bhouri, M.; Kahwaji, S.; Groulx, D.; White, M.A. Experimental Investigation of Thermal Management of Tablet Computers Using Phase Change Materials (PCMs). In Proceedings of the ASME 2016 Summer Heat Transfer Conference, Washington, DC, USA, 10-14 July 2016.

22. Ahmed, T. Development of a Novel Thermal Management Technology of Tablet Computers Using Phase Change Materials. Master's Thesis, Dalhousie University, Halifax, NS, Canada, 2016.

23. Sarvar, F.; Poole, N.J.; Witting, P.A. PCB glass-fibre laminates: Thermal conductivity measurements and their effect on simulation. J. Electron. Mater. 1990, 19, 1345-1350. [CrossRef]

24. Desgrosseilliers, L.; Groulx, D.; White, M.A. Heat conduction in laminate multilayer bodies with applied finite heat source. Int. J. Therm. Sci. 2013, 72, 47-59. [CrossRef]

25. Sim, C.; Loh, J.S. Fanless Design for Embedded Applications. Intel Technol. J. 2009, 13, 13.

(c) 2019 by the authors. Licensee MDPI, Basel, Switzerland. This article is an open access article distributed under the terms and conditions of the Creative Commons Attribution (CC BY) license (http:/ / creativecommons.org/licenses/by/4.0/). 